\title{
EBSD Analysis and Hot Tensile Properties of Pulsed Current Gas Tungsten Arc Welded Super 304h Austenitic Stainless Steel Joints
}

\author{
Vinoth Kumar $\mathbf{M}^{1}$, Rao $\mathbf{A G}^{2}$ and Balasubramanian $\mathbf{V}^{3 *}$
}

${ }^{1}$ Department of Mechanical Engineering, Hindustan Institute of Technology and Science, Hindustan University, Chennai, India

${ }^{2}$ Scientist-D, Naval Materials Research Laboratory (NMRL), Ambernath, Mumbai, India

${ }^{3}$ Centre for Materials Joining and Research (CEMAJOR), Department of Manufacturing Engineering, Annamalai University, Annamalai Nagar, Tamilnadu, India

\begin{abstract}
Super $304 \mathrm{H}$ austenitic stainless steel tubes containing 2.3 to 3 (\%wt) of $\mathrm{Cu}$ is mainly used in superheaters and reheater of ultra-supercritical boilers. Welding high alloyed steels such as stainless steels can result in local variation of alloying elements within the weld metal and such segregation may affect the high temperature properties of the weld joint. It is preferable to control the solidification structure of the weld by altering the prevailing thermal gradients in the weld pool during welding. The effect of current pulsing on microstructure and hot tensile properties of filler added gas tungsten arc welding (GTAW) of super $304 \mathrm{H}$ is studied. Current pulsing is found to be beneficial in improving the hot tensile properties of super $304 \mathrm{H}$ GTAW joints at all test temperature, which is attributed to the grain refinement, increase in frequency of high angle grain boundaries, reduced segregation and finer carbonitrides precipitation.
\end{abstract}

Keywords: Super 304H; Gas tungsten arc welding; Pulsed current; Hot tensile properties; Microstructure

\section{Introduction}

The need to increase the efficiency of the power plants and thereby to achieve, reduction in $\mathrm{Co}_{2}$ emissions can be attained by increasing the parameters of steam cycles. The main challenge in building power plants with advanced steam cycles is the availability of construction materials. Newer alloys are being developed and identified for the requirement of such power plants with advanced steam cycles. In such effort, super $304 \mathrm{H}$ stainless steel is proposed for use in super heater and reheater tubings of ultra-supercritical boilers [1]. Super $304 \mathrm{H}$ is capable of operating in steam temperatures of about $600^{\circ} \mathrm{C}$, with excellent resistance corrosion and creep. Super $304 \mathrm{H}$ with addition of 2.3 to 3 (\% wt) of $\mathrm{Cu}$ results in increased creep strength of the alloy, offered by the fine, stable, coherent $\mathrm{Cu}$-rich precipitates evolve during exposure to creep conditions [1-3].

In terms of weldability, $\mathrm{Cu}$ may slightly increases the hot cracking sensitivity and with regard to weld metal the effect of $\mathrm{Cu}$ needs to be investigated [4]. Austenitic stainless steels welded by constant current gas tungsten arc welding (CC-GTAW) produce coarse columnar grains in the fusion zone of welds and such microstructure's can result in inferior mechanical properties than the parent metal [5]. Welding high alloyed steels, such as stainless steels result in inhomogeneous weld metal with local compositional variations within the microstructure, and which can attributed to segregation of alloying elements during weld metal solidification. Segregation may result in weld joint with inferior room and high temperature properties than the parent metal.

It is preferable to control the solidification structure of the fusion zone in weld by altering the prevailing thermal gradients in the weld pool during welding [6]. In pulsed current gas tungsten arc welding (PC-GTAW) process the welding current is pulsed between high and low value for different time intervals at a pulsing frequency. The high current pulse will bring the weld zone above the melting point while the low current period in the pulse allows the weld pool to partially solidify and maintain a consistent arc. The weld bead is observed as a series of over lapped spot weld in which the overlap depends on the pulsing frequency $[5,7]$.

Sen et al. [8] reported that $\mathrm{Cu}$ addition to $304 \mathrm{H}$ stainless steel does not embrittle the alloy during exposure to high temperature. Ha and Jung [9] reported the suitability of the steel for ultra-supercritical application. Works carried out by Yang et al. [10], Li et al. [11], Bai et al. [12] on super $304 \mathrm{H}$ boiler grade austenitic stainless steel revealed its good microstructural stability during high temperature exposure. However, the work on PC-GTAW of super $304 \mathrm{H}$ in open literature is very scant. Hence in this investigation it is planned to study the effect of current pulsing on microstructure and hot tensile properties of filler added GTAW joints of super $304 \mathrm{H}$ austenitic stainless steel.

\section{Experimental Details}

Super $304 \mathrm{H}$ austenitic stainless steel tubes of outer diameter 57.1 $\mathrm{mm}$ and wall thickness of $3.5 \mathrm{~mm}$ was used in this investigation. The chemical composition of the tubes in as-received condition and filler metal are given in Table 1. Joints with single $\mathrm{V}$ butt edge preparation were welded with filler addition using CC-GTAW and PC-GTAW processes. Argon was used as shielding and purging gas with flow rate of 12 and 10 liters per minute respectively, to prevent oxidation of the welds. The welding parameters used to fabricate the joints are shown in Table 2.

The photograph of the joints welded by CC-GTAW and PCGTAW is shown in Figure 1a. Joints are inspected for defects and tensile specimens were extracted using wire-cut electric discharge machining, as per the dimensions shown in Figure 1b. Tensile tests were carried out using universal testing machine (UTM) under the constant crosshead speed mode for a nominal strain rate of $1 \times 10^{-3} \mathrm{~S}^{-1}$ at

${ }^{*}$ Corresponding author: Balasubramanian $\mathrm{V}$, Centre for Materials Joining and Research (CEMAJOR), Department of Manufacturing Engineering, Annamalai University, Annamalai Nagar, Tamilnadu 608002, Tel: +91-9443412249; E-mail: visvabalu@yahoo.com

Received March 23, 2016; Accepted April 16, 2016; Published April 26, 2016

Citation: Vinoth Kumar M, Rao AG, Balasubramanian V (2016) EBSD Analysis and Hot Tensile Properties of Pulsed Current Gas Tungsten Arc Welded Super 304h Austenitic Stainless Steel Joints. J Steel Struct Constr 2: 110. doi:10.4172/24720437.1000110

Copyright: (c) 2016 Vinoth Kumar M, et al. This is an open-access article distributed under the terms of the Creative Commons Attribution License, which permits unrestricted use, distribution, and reproduction in any medium, provided the original author and source are credited. 
Citation: Vinoth Kumar M, Rao AG, Balasubramanian V (2016) EBSD Analysis and Hot Tensile Properties of Pulsed Current Gas Tungsten Arc Welded Super 304h Austenitic Stainless Steel Joints. J Steel Struct Constr 2: 110. doi:10.4172/2472-0437.1000110

Page 2 of 6

\begin{tabular}{|c|c|c|c|c|c|c|c|c|c|c|c|c|c|}
\hline & C & $\mathrm{Si}$ & $\mathrm{Mn}$ & $\mathrm{P}$ & $S$ & $\mathrm{Cr}$ & $\mathrm{Ni}$ & $\mathrm{N}$ & $\mathrm{Cu}$ & $\mathrm{Nb}$ & Mo & B & $\mathrm{Al}$ \\
\hline PM & 0.086 & 0.23 & 0.81 & 0.021 & 0.0003 & 18.18 & 9.06 & 0.095 & 3.080 & 0.045 & - & 0.0039 & 0.01 \\
\hline FM & 0.1 & 0.3 & 3.3 & $<0.01$ & $<0.01$ & 18.3 & 15.7 & 0.16 & 2.9 & 0.5 & 0.7 & - & - \\
\hline
\end{tabular}

Table 1: Chemical composition (wt\%) of parent metal (PM) and filler metal (FM).

\begin{tabular}{|c|c|c|}
\hline & CC-GTAW & PC-GTAW \\
\hline Current (A) & 75 & - \\
\hline Base current (A) & - & 45 \\
\hline Peak Current (A) & - & 75 \\
\hline Pulse on time (\%) & - & 75 \\
\hline Pulse Frequency $(\mathrm{Hz})$ & - & 10 \\
\hline Voltage $(\mathrm{V})$ & 11.3 & 11 \\
\hline Welding speed $(\mathrm{mm} / \mathrm{min})$ & 75 & 67 \\
\hline Heat input $(\mathrm{kJ} / \mathrm{mm})$ & 0.68 & 0.66 \\
\hline
\end{tabular}

Table 2: GTAW parameters used to fabricate the joints.

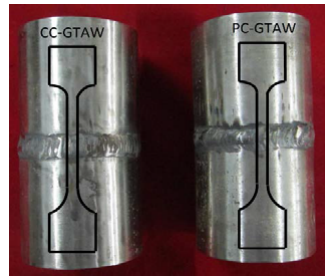

a.Joints welded

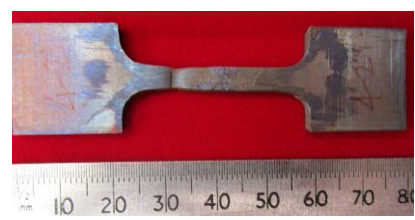

c. CC-GTAW

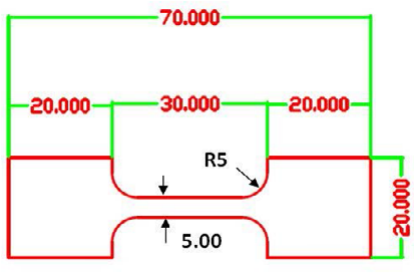

b.wire-cut electric discharge machining

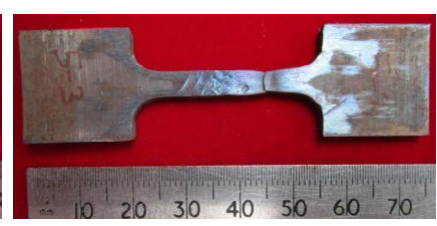

d.PC-GTAW
Figure 1: Photograph of welded tubes and tensile specimen.

test temperatures of room temperature (RT), $550^{\circ} \mathrm{C}, 600^{\circ} \mathrm{C}$ and $650^{\circ} \mathrm{C}$. The UTM system was equipped with a three-zone resistance heating furnace and a computer with data acquisition system for obtaining digital load-elongation data. The photograph of hot tensile specimens of CC-GTAW and PC-GTAW joints after test are shown in Figures 1c and $1 \mathrm{~d}$ respectively. The hardness was measured along the weld center line using Vickers micro hardness tester with a load of $500 \mathrm{~g}$ and dwell time of $15 \mathrm{~s}$. The volume percentage of delta ferrite in cross section of the weld joint and on the face of the welds were determined using (make: Fischer) ferrite scope.

The specimen for microstructural examination was prepared using standard metallographic techniques and etched with 3 parts HCL and 1 part $\mathrm{HNO}_{3}$ for 5-10 s to reveal the microstructural features. The microstructural examination of the weld joint was carried out using light optical microscope (OM) and scanning electron microscopy (SEM). Compositional variation within the weld regions were analysed using energy dispersive spectroscopy (EDS) attached with SEM. $\mathrm{X}$-ray Diffraction (XRD) analysis of the weld metals were carried out to identify and confirm the phases. Electron back scatter diffraction (EBSD) was employed to analyse the grain size distrubution, grain orientations, and misorientations of weld metal. The fracture surfaces of the tensile specimens were analysed using SEM to reveal the mode of fracture.

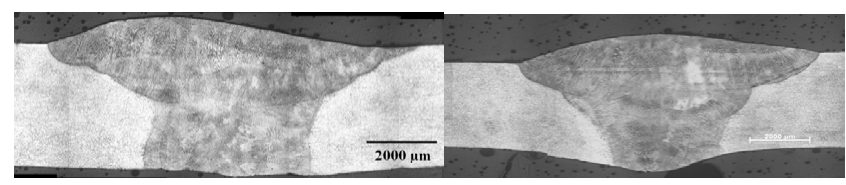

a. Macrograph

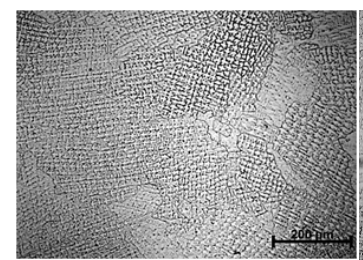

c. Weld metal

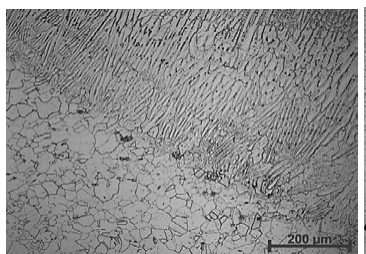

e. Fusion line b. Macrograph

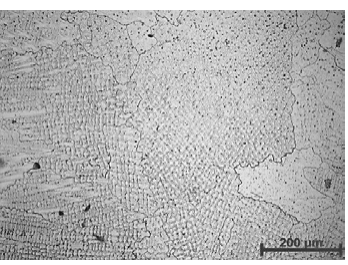

d. Weld metal

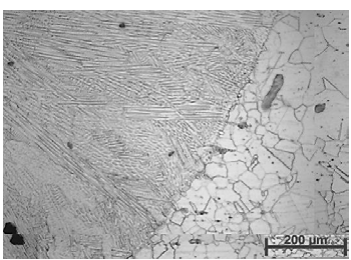

f. Weld metal
Figure 2: Optical microstructure of CC-GTAW and PC-GTAW joints.

\section{Results}

\section{Microstructure}

Macrographs of the CC-GTAW and PC-GTAW joints are shown in Figures $2 \mathrm{a}$ and $2 \mathrm{~b}$ respectively, macrographs reveal the complete fusion of the tube joint with no macro defects. Figures $2 \mathrm{c}$ and $2 \mathrm{~d}$ show the weld metal microstructure of CC-GTAW and PC-GTAW joints, consists of equiaxed austenitic grains. Figures $2 \mathrm{e}$ and $2 \mathrm{f}$ show the weld fusion line, consists of columnar austenitic grains preferentially oriented towards the weld centre, evidencing the epitaxial grain growth occurred in those regions. The heat affected zone (HAZ) of both CCGTAW and PC-GTAW joints consist of coarser grains than the parent metal.

SEM micrograph of weld metal of CC-GTAW and PC-GTAW joints is shown in Figures 3a and $3 b$ respectively, weld metals invariably consist of fully austenitic grains with no delta ferrite and the migrated grain boundaries in the weld metal is indicated by arrow in Figure $3 \mathrm{~b}$. SEM images of fusion line of CC-GTAW and PC-GTAW joints are shown in Figures $3 c$ and $3 d$, which reveals the absence of delta ferrite near fusion line. EDS elemental mapping of weld metals shown in Figures $4 \mathrm{a}-4 \mathrm{f}$, reveals that the precipitates in weld metal are Mo and $\mathrm{Nb}$ rich carbonitrides which were intentionally added in the filler wire to stabilize the higher carbon content. EDS line scan of the weld metal grain boundary shown in Figures $4 \mathrm{~g}$ and $4 \mathrm{~h}$ reveals no segregation of $\mathrm{Cr}$ and $\mathrm{Ni}$ to the grain boundaries. The ferrite measurement using ferrite scope revealed no indication of delta ferrite in the welds of both CC-GTAW and PC-GTAW joints.

The XRD pattern of weld metals of CC-GTAW and PC-GTAW 
Citation: Vinoth Kumar M, Rao AG, Balasubramanian V (2016) EBSD Analysis and Hot Tensile Properties of Pulsed Current Gas Tungsten Arc Welded Super 304h Austenitic Stainless Steel Joints. J Steel Struct Constr 2: 110. doi:10.4172/2472-0437.1000110

Page 3 of 6

\section{CC-GTAW}

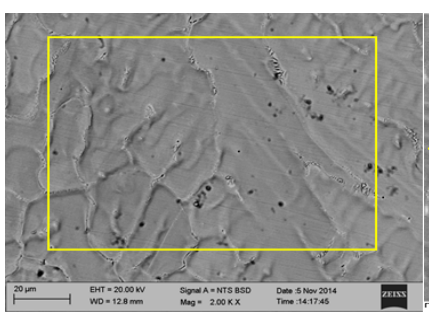

a. Weld center

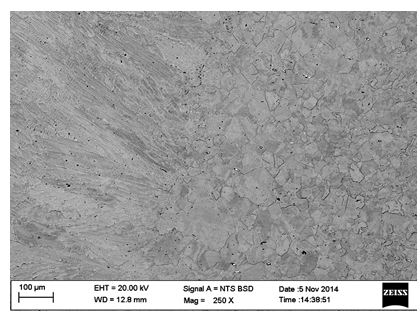

c. Fusion lined
PC-GTAW

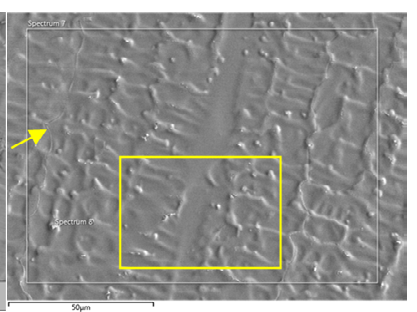

b. Weld center

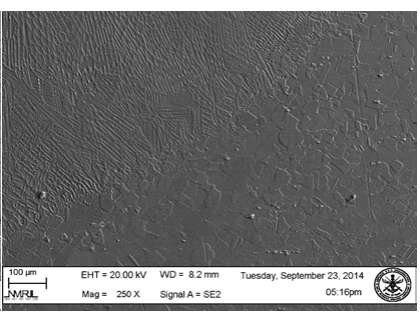

d. Fusion line

Figure 3: SEM micrograph of CC-GTAW and PC-GTAW joints.

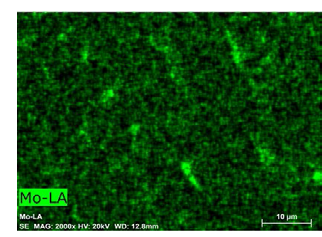

a. EDS elemental map of Mo

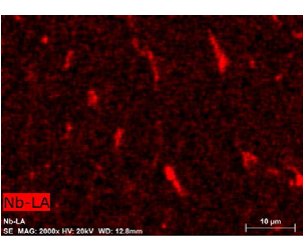

c. EDS elemental map of $\mathrm{Nb}$

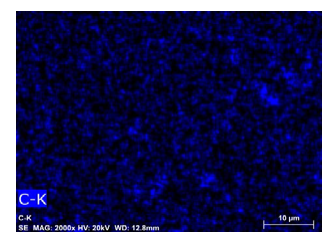

e. EDS elemental map of $\mathrm{C}$

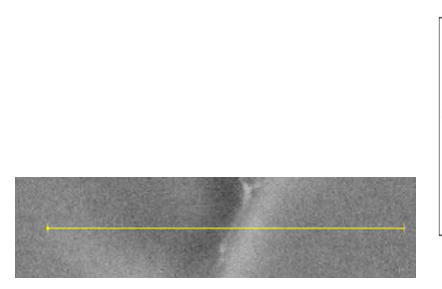

g. EDS Line scan of grain boundary h. EDS Line scan of grain boundary
-GTAW and PC-GTAW joints.

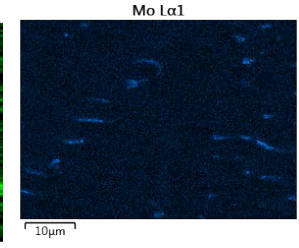

b. EDS elemental map of Mo

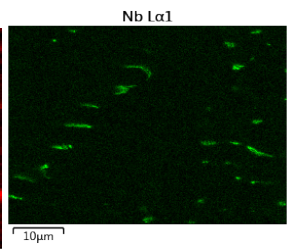

d. EDS elemental map of $\mathrm{Nb}$

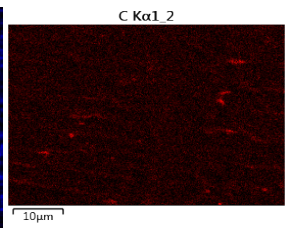

f. EDS elemental map of C

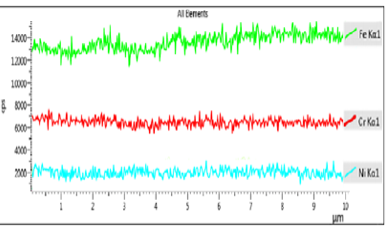

joints shown in Figures $5 \mathrm{a}$ and $5 \mathrm{~b}$ reveals the absence of delta ferrite. The XRD patterns confirm the presence of fully austenitic weld metal with $\mathrm{Nb}$ and Mo carbonitrides in the weld metal of both joints.

\section{EBSD analysis}

The EBSD pole figures of cross section of CC-GTAW and PCGTAW joints are shown in Figures $6 \mathrm{a}$ and $6 \mathrm{~b}$ respectively. From the pole figures, it can be inferred that, the dendrites in the weld metal does not exist as a single entity, but it is actually part of a larger grain, where the weld metal consists of coarse grains than the parent metal [13]. The interface in the pole figure reveals epitaxial grain growth, planar solidification and grain growth in the HAZ. The grain size distribution in the weld metal of CC-GTAW and PC-GTAW joints are shown in Figures $6 \mathrm{c}$ and $6 \mathrm{~d}$ respectively. From the distribution chart, it can be inferred that the number of finer grains $(<70 \mu \mathrm{m})$ in the weld metal is higher in the PC-GTAW than the CC-GTAW, which attributes the grain refinement achieved in the weld metal due to current pulsing. The relative frequency of misorientation between the grains in the welds of CC-GTAW and PC-GTAW joints are shown in Figures 6e and 6f. The presence of grains boundaries with lower degree of misorientation $\left(<15^{\circ}\right)$ are referred as low angle grain boundaries and are found to be less frequent in case of PC-GTAW joint than the CC-GTAW joint.

\section{Tensile properties}

The transverse tensile properties of CC-GTAW and PC-GTAW joints of super $304 \mathrm{H}$ at various test temperatures are presented in Table 3. PC-GTAW joint exhibited marginal increase in tensile strength and
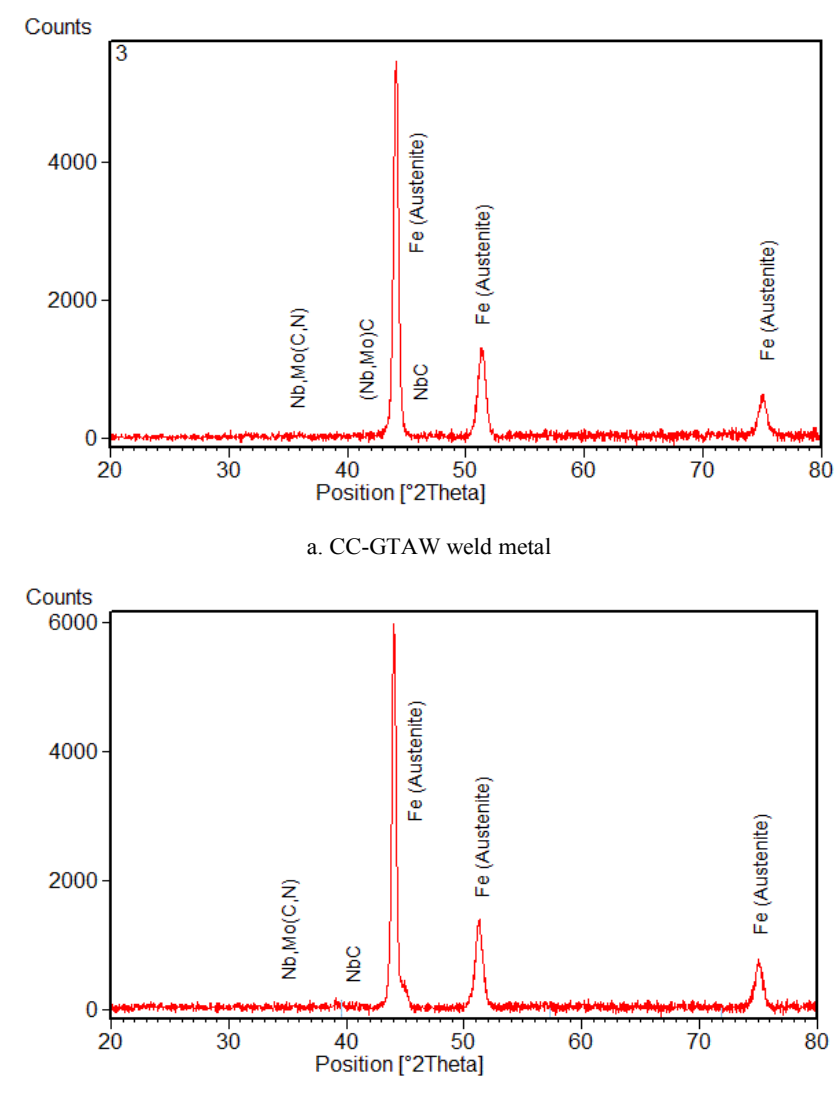

b. PC-GTAW weld metal

Figure 5: XRD analysis of CC-GTAW and PC-GTAW joints. 
Citation: Vinoth Kumar M, Rao AG, Balasubramanian V (2016) EBSD Analysis and Hot Tensile Properties of Pulsed Current Gas Tungsten Arc Welded Super 304h Austenitic Stainless Steel Joints. J Steel Struct Constr 2: 110. doi:10.4172/2472-0437.1000110

\section{CC-GTAW}

\section{PC-GTAW}

\section{$\overbrace{1}$}

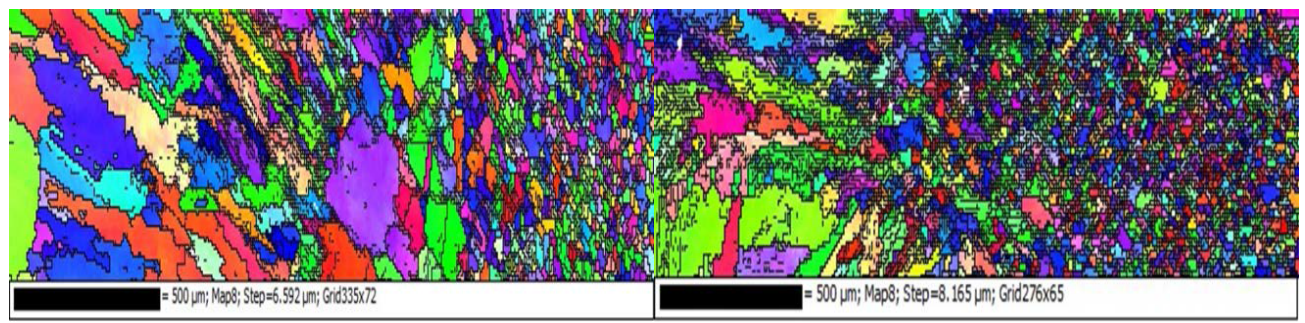

a. Orientation map of weld interface

b. Orientation map of weld interface

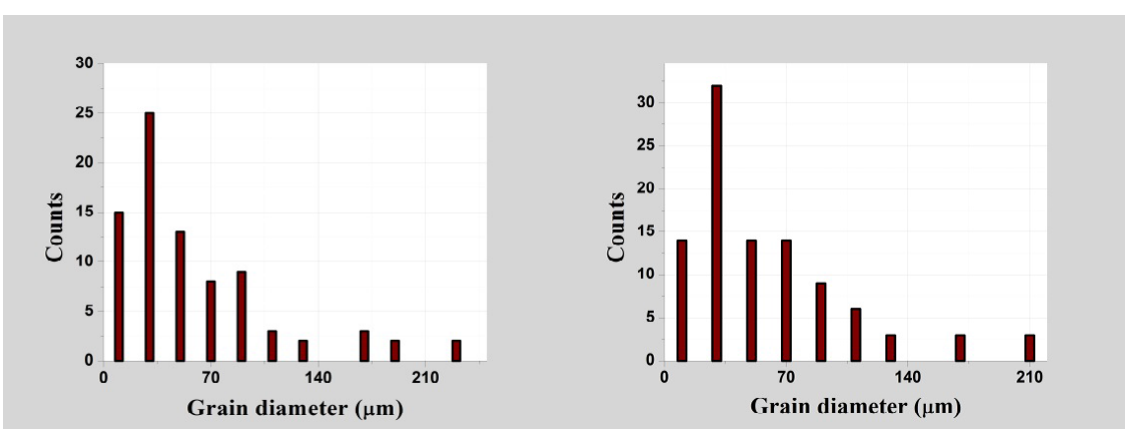

c. Grain size distribution

d. Grain size distribution
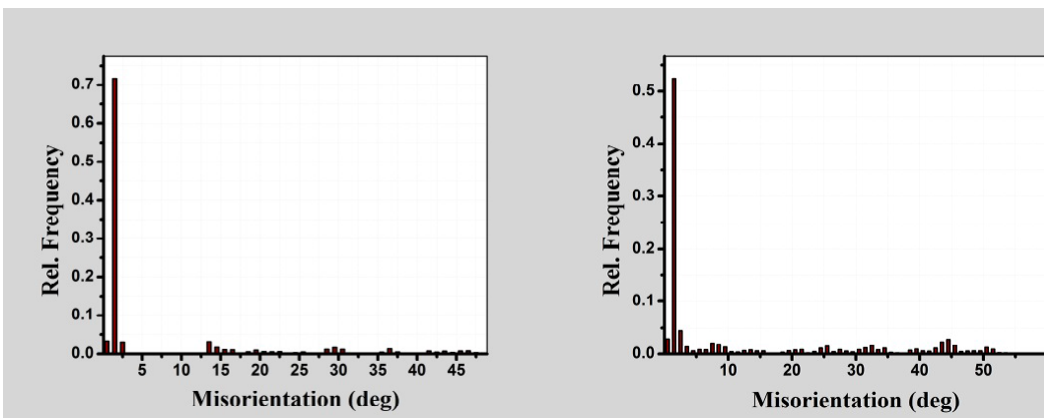

e. Misorientation fraction of boundaries f. Misorientation fraction of boundaries

Figure 6: EBSD analysis of CC-GTAW and PC-GTAW joints.

\begin{tabular}{|c|c|c|c|c|c|}
\hline & $\begin{array}{c}\text { Test } \\
\text { temperature } \\
\left(0^{\circ} \mathrm{C}\right)\end{array}$ & $\begin{array}{l}0.2 \% \text { Yield } \\
\text { strength } \\
\text { (MPa) }\end{array}$ & $\begin{array}{l}\text { Ultimate tensile } \\
\text { strength (MPa) }\end{array}$ & $\begin{array}{l}\text { Elongation in } \\
25 \mathrm{~mm} \text { gauge } \\
\text { length (\%) }\end{array}$ & $\begin{array}{l}\text { Failure } \\
\text { location }\end{array}$ \\
\hline \multirow{4}{*}{ 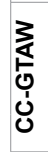 } & RT & 349.6 & 614.6 & 52.3 & Parent metal \\
\hline & 550 & 247.3 & 470.2 & 39.2 & Parent metal \\
\hline & 600 & 196.3 & 413.6 & 36.6 & Parent metal \\
\hline & 650 & 240.8 & 392.7 & 27.3 & Parent metal \\
\hline \multirow{4}{*}{ 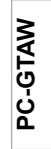 } & RT & 365.5 & 621.3 & 56.8 & Parent metal \\
\hline & 550 & 292 & 481.7 & 41.9 & Parent metal \\
\hline & 600 & 236.2 & 434.8 & 40.6 & Parent metal \\
\hline & 650 & 293.5 & 409.5 & 30.3 & Parent metal \\
\hline
\end{tabular}

Table 3: Tensile properties of CC-GTAW and PC-GTAW joints of super 304H.

percentage of elongation than the CC-GTAW joints at all the test temperatures. The tensile strength and elongation of both the joints decreased with increase in test temperature. The failure was located in the parent metal in both CC-GTAW and PC-GTAW joints at all test temperatures.

\section{Micro hardness}

The micro hardness profiles measured across the weld center line of CC-GTAW and PC-GTAW joints in the mid thickness are presented in Figure 7. The highest hardness value was recorded in the weld metal of both joint however, PC-GTAW weld metal exhibited lower hardness than the CC-GTAW joint. Large variations in hardness values within the weld metal region were observed for CC-GTAW joint than the PCGTAW joint, owing to their inhomogeneous microstructure. Lowest hardness across the joints was recorded in the weld metal close to the fusion line, probably the unmixed zone (UMZ). The HAZ region of 
Citation: Vinoth Kumar M, Rao AG, Balasubramanian V (2016) EBSD Analysis and Hot Tensile Properties of Pulsed Current Gas Tungsten Arc Welded Super 304h Austenitic Stainless Steel Joints. J Steel Struct Constr 2: 110. doi:10.4172/2472-0437.1000110

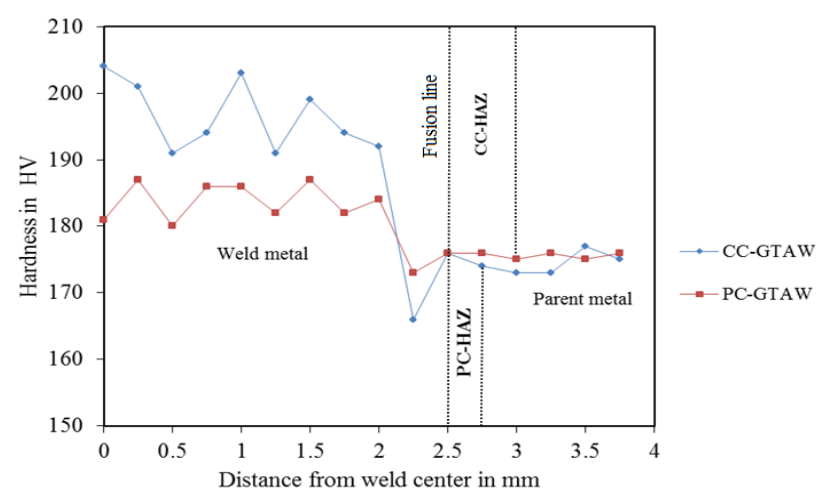

Figure 7: Hardness profile of CC-GTAW and PC-GTAW joints.

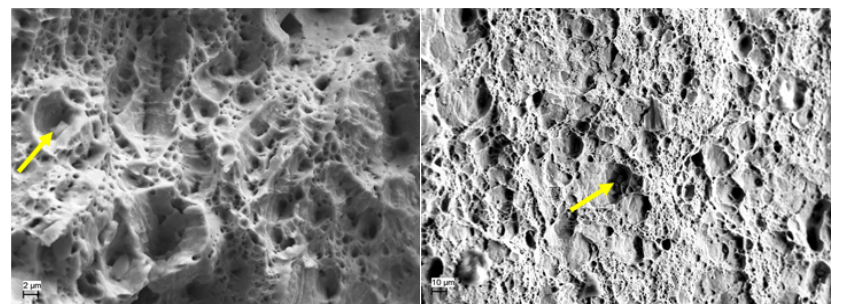

a. Room temperature

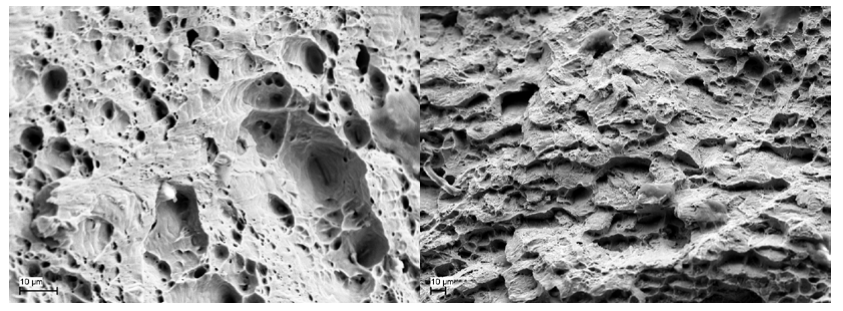

c. $550^{\circ} \mathrm{C}$

d. $550^{\circ} \mathrm{C}$

Figure 8: SEM fractographs of CC-GTAW and PC-GTAW tensile specimens.

both CC-GTAW and PC-GTAW joint has not undergone softening due to welding and retained its hardness equivalent to that of the parent metal $(175 \mathrm{HV})$.

\section{Fracture surfaces}

SEM fractographs of tensile specimens are shown in Figure 8. In all the cases, fracture occurred in parent metal and the features observed are similar in CC-GTAW and PC-GTAW joints. Fracture surface of CC-GTAW and PC-GTAW joint tested at RT are shown in Figures 8a and $8 \mathrm{~b}$ respectively. The fracture was ductile for both joints tested at RT, with fine dimples around the voids, which are associated with the precipitates, acted as crack initiation sites. Figures $8 \mathrm{c}$ and $8 \mathrm{~d}$ show the fracture surface of CC-GTAW and PC-GTAW joints tested at $550^{\circ} \mathrm{C}$ reveals more featureless region with elongated voids and dimples. The joints tested at $550^{\circ} \mathrm{C}$ failed in less ductile manner than the joints tested at RT, and it is also evident from the tensile elongation (Table 3).

\section{Discussion}

PC-GTAW joint exhibited higher tensile strength and elongation values than CC-GTAW at all test temperatures with the failure at the parent metal. The mode of solidification and amount of delta ferrite in stainless steel welds can be predicted using WRC-1992 constitution diagram. The $\mathrm{Cr}$ and $\mathrm{Ni}$ equivalents of filler metal were calculated as 19.4 and 23.1 respectively and the weld metal was predicted to solidify in A-Mode with fully austenitic weld metal. The microstructural analysis of CC-GTAW and PC-GTAW joints revealed fully austenitic weld metal, with no delta ferrite as predicted. The addition of carbide forming Mo and increased addition of $\mathrm{Nb}$ to the filler metal had resulted in formation of $\mathrm{Mo}$ and $\mathrm{Nb}$ rich carbonitirdes (Figures $4 \mathrm{a}-$ 4f). Hence the risk of forming other detrimental carbides in the weld metal of super $304 \mathrm{H}$ with high carbon content was reduced. Periodic pulsing of welding current in PC-GTAW, impose thermal variation in the weld pool to enhance the flow of molten metal in the weld pool and help to reduce the compositional variation within the weld metal [5-7]. Current pulsing resulted in grain refinement (Figures $6 \mathrm{c}$ and $6 \mathrm{~d}$ ), with more high angle grain boundaries (Figures 6e and 6f).

The higher strength of the PC-GTAW joint is attributed to the presence of fine carbonitrides in the weld metal, higher number of high angle boundaries, and finer grain size which offers greater resistance to dislocation motion $[14,15]$. The fusion zone forms between the fusion line and weld metal, which denotes the actual amount of base metal melted during welding. The difference in composition of the parent metal and filler metal result in formation of UMZ, which is similar to cast parent metal and hence the lowest hardness was recorded in the region. The HAZ of both CC-GTAW and PC-GTAW retained its hardness value on par with parent metal, due to the highly stable microstructure of the super $304 \mathrm{H}$ at elevated temperatures [11]. The drop in yield strength of the weld joint at $600^{\circ} \mathrm{C}$ can be attributed to the ductility dip encountered in super $304 \mathrm{H}$ parent metal at that temperature range. The fracture was located in the parent metal for both the weld joints tested at all temperatures. Parent metal was used in solution annealed condition, with fine nitride precipitates to provide required grain refinement during tube manufacturing process. Such precipitates (indicated by arrow in Figure 8) may act as probable crack initiation sites during fracture at room temperature, while the fracture is found to be increasingly brittle with increase in test temperature. The decrease in elongation (ductility) with increase in temperature for both the joints was attributed to the lack of dislocations to undergo deformation. The dislocations which are available at RT to undergo plastic deformation are annihilated at high temperature due the recovery process resulted in reduction in elongation at higher temperatures [16].

\section{Conclusions}

1. PC-GTAW joint exhibited higher tensile strength and ductility (percentage of elongation) than the CC-GTAW joint at all test temperatures. Failure was located in the parent metal for all the joints tested at both room and high temperature. Hence the weld metals of both CC-GTAW and PC-GTAW joint exhibited higher strength than the parent metal.

2. Current pulsing was found to be beneficial in improving the tensile properties of GTAW joints of super $304 \mathrm{H}$ at all test temperatures. The improvement in strength was achieved through grain refinement, increasing the frequency of high angle grain boundaries, reduced segregation and precipitation of finer carbonitrides.

\section{Acknowledgement}

The authors wish to express their sincere thanks to M/s Mailam India Ltd Pondicherry, India for providing financial assistance to carry out this research work through the Mailam India Research (MIR) Fellowship, M/s Salzgitter Mannesmann Stainless Tubes Italia Srl, Italy for supplying the super $304 \mathrm{H}$ tubes required to carry out this work, and the Director, Naval Materials Research Laboratory (NMRL), Ambernath, Mumbai for providing the facility to carry out hot tensile testing. 
Citation: Vinoth Kumar M, Rao AG, Balasubramanian V (2016) EBSD Analysis and Hot Tensile Properties of Pulsed Current Gas Tungsten Arc Welded Super 304h Austenitic Stainless Steel Joints. J Steel Struct Constr 2: 110. doi:10.4172/2472-0437.1000110

\section{References}

1. Viswanathan R, Bakker WT (2000) Materials for Ultra Supercritical Fossil Power Plants. Technical report -114750, Electric Power Research Institute, USA

2. Chi CY, Yu HY, Dong JX, Xie XS, Cui ZQ, et al. (2011) Coherent Precipitation of Copper in Super304H Austenite Steel. Materials Science and Engineering: A 584: 57-62.

3. Tan S, Chen WD, Wang F, Chang YA (2010) Property Prediction Using Hierarchical Regression Model Based on Calibration. Iron Steel Res Int 17: 30-35.

4. Erich Folkhard (1988) Welding Metallurgy of Stainless Steels. In Gunther Rabensteiner, Ernst Perteneder, Heinz Schabereiter, Josef Tosch (eds.) Springer-Verlag Wien, New York.

5. Reddy AA, Guha B, Achar DRG (2002) Finite Element Modeling of ThreeDimensional Transient Heat Transfer in Stainless Steel (304) Pulsed Gta Weldments. Numer Heat Transfer A J 41: 41-64.

6. Balasubramanian M, Jayabalan V, Balasubramanian V (2008) Optimizing the Pulsed Current GTAW Parameters to Attain Maximum Impact Toughness. Mater Manuf Process J 23: 69-73.

7. Giridharan PK, Murugan N (2009) Optimization of Pulsed GTA Welding Process Parameters for the Welding of AISI 304L Stainless Steel Sheets. Adv Manuf Technol J 40: 478-489.

8. Sen I, Amankwah E, Kumar NS, Fleury E, Ishi OK, et al. (2011) Microstructure and Mechanical Properties of Annealed SUS 304H Austenitic Stainless Steel with Copper. Mater Sci Eng A J 528: 4491-4499.
9. Ha VT, Jung WS (2012) Creep Behavior and Microstructure Evolution at $750^{\circ} \mathrm{C}$ in a New Precipitation-Strengthened Heat-Resistant Austenitic Stainless Steel. Mater Sci Eng A J 558: 103-111.

10. Yang $H$, Peng $F$, Miao $X$, Yang $X(2006)$ Investigation of the Aging Behavior on Boiler Steel Tube Super 304H. Press Equip Sys J 4: 96-99.

11. Hu X, Zou G, Dong SJ, Lee MY, Jung JP, et al. (2010) Effects of Steel Coatings on Electrode Life in Resistance Spot Welding of Galvannealed Steel Sheets. Mater Trans J 51: 2236-2242.

12. Bai JW, Liu PP, Zhu YM, Li XM, Chi CY, et al. (2013) Coherent Precipitation of Copper in Super304H Austenite Steel. Mater Sci Eng A J 584: 57-62.

13. Kell J, Tyrer JR, Higginson RL, Thomson RC (2005) Microstructural Characterization of Autogenous Laser Welds on 316L Stainless Steel Using EBSD and EDS. Microsco J 217: 167-173.

14. Wang SQ, Liu JH, Chen DL (2014) Effect of Strain Rate and Temperature on Strain Hardening Behavior of a Dissimilar Joint Between Ti-6Al-4V and Ti17 Alloys. Mater Des J 56: 174-184.

15. Fan Z, Mingzhi H, Deke S (1989) The Relationship Between the StrainHardening Exponent $\mathrm{n}$ and the Microstructure of Metals. Mater Sci Eng A J 122: $211-213$.

16. Choudhary BK, Palaparti DPR (2012) Influence of Strain Rate and Temperature on Tensile Stress-Strain and Work Hardening Behaviour of $9 \mathrm{Cr}-1 \mathrm{Mo}$ Ferritic Steel. Mater Sci Eng A J 538: 110-117. 